\title{
Bonding, Bridging, and Linking: Social Capital and Its Potential Health Impact among Refugees in Their Resettlement Countries
}

\author{
Huaibo Xin \\ Department of Applied Health, Southern Illinois University Edwardsville, USA
}

Copyright $\bigcirc 2018$ by authors, all rights reserved. Authors agree that this article remains permanently open access under the terms of the Creative Commons Attribution License 4.0 International License

\begin{abstract}
Literature has highly emphasized the importance of social capital on health and mental health. This study aimed to identify the patterns of the structures and relations of social capital among refugee populations through a systematic review so as to promote their health by fostering the growth of their social capital in their resettlement countries. A total of 1,476 peer-reviewed journal articles, book chapters, reports, theses, dissertations, and commentaries, related to refugees' social capital building were thoroughly reviewed. Thirty-seven articles were included in the final theme analysis. Information was organized based on the three categories: bonding capital, bridge capital, and linking capital. Findings indicated that refugees in their resettlement countries commonly relied on religious practice, their ethnic organizations, school/workplaces, social and sports events, and social media to develop all three categories of social capital. Additionally, they built both their bonding and bridging capital through family, neighbors, and friends. They were further linked to a broader spectrum through both government and non-government organizations, and transnational network. Literature also revealed barriers that refugees encountered in capital building. The needs of both a policy change and research in identifying more effective and innovative strategies of helping refugees in social integration should be addressed.
\end{abstract}

Keywords Social Capital, Networks, Refugees, Health

\section{Introduction}

The concept of social capital has evolved and been defined by many scholars throughout the years. In summary, it was described as the glue to hold individuals and a community together, which includes the relations and structures within a community, such as trust, attitudes, norms of reciprocity, expectations, civic engagement, community cohesion, sense of belonging, and networks. It facilitates the coordination and collaboration among individuals and social organizations and improves the efficiency of the functions of a society [1-4]. It has three different types of network resources including bonding social capital to bring people/groups who already know each other together; bridging social capital to bring people/groups who previously did not know each other and are outside each other's group together through interactions during any common tasks within a community; linking social capital to bring people/groups together from "different social strata in a hierarchy where power, social status, and wealth are accessed by different groups" [3]. Social capital has been demonstrated to be a determinant of many aspects of health, such as physical health, mental health, emotional health and social health, among different populations across the lifespan [1-20]. It improves individuals/communities' access to health relevant information; provides individuals/communities with informal healthcare and support in case of illness; and improves the effectiveness of health advocacy through well-organized and connected groups [1].

In recent literature, for example, a study examining the relationship between individual social capital and self-reported health was done among individuals from eight transition countries of Central and Eastern Europe and the Commonwealth of Independent States, including Armenia, Belarus, Georgia, Kazakhstan, Kyrgyzstan, Moldova, Russia, and Ukraine. Social capital was measured by degree of interpersonal trust, levels of participation in local organizations, and social isolation. Health was measured by the Living Conditions, Lifestyles, and Health survey. Although health varied by country, regardless of the political climate in each country, both trust and social isolation were independently associated 
with individuals' general health, access to healthcare, living conditions, etc. either in a positive or negative way [5]. Similarly, Hurtado and his colleagues conducted a study among 3,025 participants in Columbia. Health was self-rated from very good to poor health, and individual social capital was also measured using indicators like interpersonal trust, reciprocity, associational membership, civic participation, volunteering, and non-electoral political participation. Interpersonal trust, reciprocity, and associational membership were significantly associated with better health [6]. Poortinga looked into the relationships between different types of social capital and individual health/community deprivation among 17,572 participants in England. Bonding social cohesion related to bonding social capital, bridging social cohesion related to bridging social capital, and heterogeneous relationships including socioeconomic status and ethnicity, political participation, political activism, political efficacy, and political trust related to linking social capital, were evaluated respectively. Unsurprisingly, most of these aspects were significantly related to neighborhood deprivation and individual health. Social capital may also serve as a pathway between neighborhood deprivation and individual health [7]. In Netherlands, neighborhood social capital was measured using a national representative sample with 61,235 respondents in 3,273 neighborhoods. Participants' perception of their neighborhood cohesion was surveyed. Findings suggested that higher collective social capital at the neighborhood level led to better residents' health in general [8]. Whether it is at an individual or an aggregated level, the linkage between social capital and incidence and prevalence of morbidity/mortality of different health outcomes has been consistently proven true among many other populations in many other countries (e.g., Finland, China, U.S.) [9-11].

Literature further emphasized the significance of the impact of social capital on mental health [12-21]. A total of 2,624 adult residents from 300 census tracks in Canada, who was part of the 2008 Montreal Neighbourhood Networks and Healthy Ageing Study were surveyed. Respondents reported their depressive symptoms using the 10-item Depression Scale, and their social capital status inside and outside of their community, including their social network, neighborhood trust, neighborhood cohesion, and community engagement. It appeared that having strong neighborhood ties, perceived neighborhood trust, perceived neighborhood cohesion reduced the likelihood of having depression [12]. Moreover, using a quasi-experimental study design, a psychological community intervention was carried out in Rwanda within an eight-month period to strengthen the social bonding and examine the relationship among sociotherapy intervention, social capital, and mental health. Cognitive social capital, social support, and civic participation were included in the social capital measurement. Comparisons made between the intervention and control groups, indicated that sociotherapy significantly fostered the intervention group's social capital, which may also subsequently improved the participants' mental health [13]. Most recently, in a longitudinal study, Landstedt and her colleagues specifically focused on the association between individuals' engagement in clubs/organizations and their depressive symptoms among 1,001 participants aged from 16-42 years old and lived in Northern Sweden. In Men, youth civic engagement could prevent them from having depressive symptoms in their adulthood, and a higher level of civic engagement could lead to a better mental health outcome [14]. It concurred with the early findings in Rothon's study focused on adolescents' family social capital and involvement in extracurricular activities, mental health, and their educational outcome in England. Regardless of their gender difference, anxiety and depression were less likely to happen to the adolescents with higher level of parental support [15]. The present study aimed to identify the patterns of the structures and relations of social capital among refugee populations through a systematic review so as to promote their health by fostering the growth of their social capital in their resettlement countries.

\section{Materials and Methods}

\subsection{Inclusion and Exclusion Criteria}

Publications published until 2018 and including peer-reviewed journal articles, reports, and book chapters related to different refugee populations' social capital, were carefully reviewed. Regardless of their demographics, refugees included in the literature were international refugees resided in a refugee camp or a resettlement country. Social capital broadly referred to social network, bonding capital, bridging capital, linking capital, social support, trust, norms of reciprocity, attitudes, expectations, sense of belonging, civic engagement, and/or community cohesion at either an individual or a community level [1-4]. The inclusive review covered both qualitative and quantitative data presented in a primary research study, a meta-analysis, a systematic review, a report, or a commentary. Publications related to asylum-seekers and immigrants were not included in this review.

\subsection{Search Strategy}

A total of 1,476 peer-reviewed journal articles, book chapters, reports, theses, dissertations, and commentaries published until 2018 were reviewed, which were obtained from several major databases, such as EBSCO, CINAHL Plus, PubMed, Medline, Medline Plus, and Google Scholar. Key search words included "social network and refugees," "social capital and refugees," and "social support, network and refugees." Only 37 peer-reviewed 
journal articles, dissertations, book chapters, and reports with a focus of refugees were adopted for the final data analysis.

\subsection{Data Extraction and Synthesis}

Information related to the broadly defined social capital, including but not limited to social network, different types of social capital, trust, community engagement, community cohesion, social norms, attitudes, and sense of belonging was extracted from the 37 publications and synthesized using the Social Capital Theory and theme analysis. Social Capital Theory was adopted as the framework to categorize the qualitative findings into three main categories: bonding capital, bridging capital, and linking capital.

\section{Results}

\subsection{Bonding Social Capital}

A total of 24 out of 37 articles identified various ways that refugees used to develop their bonding capital within each of their ethnic groups while they were away from their country of origin [22-45]. (1) Family, Friend, and Community The social ties that refugees most frequently used to receive emotional, informational, and material support were their immediate or extended families, friends, and/or community members from the same ethnic, such as Sudanese, Cambodians, Karens, Somalis, Bosnians, Afghanistani, Indochinese, Liberians, Vietnamese, Cubans, and Congolese [22-33]. Refugees stayed closely with their family members, relative, and peers who are from refugee camps, resettlement countries, and their countries of origin $[23,25,28]$. For instance, Burmese were making constant communications to maintain their family ties when they stayed at the refugee camps [23]. Secondary migration occurred among the refugees in order for themselves to be closer to their family and relatives after their initial resettlement to a host country [25]. Cohesive family relationships, including extended family, were evident among young refugees [32]. Trusted and respected community leaders also brought the refugee communities together, and were "repeatedly identified as key to strong social capital for resettling communities" [33]. (2) Religious Practice Religious practice was popular among the resettled refugees, which tied families, friends, and community members altogether and facilitated information exchange $[22,23.30,34,35]$. For instance, Southeast Asian refugees in the U.S. built a local Buddhist temple and had Buddhist monks reside there [34]; Cambodians in Canada built three new Cambodian Buddhist temples [22]. A Roman Catholic Church organized traditional Congolese masses for Congolese refugees in Canada and helped with their community bonding [35]. Sudanese Community Church, Somali Mosque, Karen Baptist Church, and other local Catholic churches facilitated community networking and provided a sense of belonging and social benefits of reciprocity in Thailand-Burma borderland, Ghana, or U.S. [23, 30]. (3) Ethnic Organization Ethnic organizations played a significant role in refugees' bonding capital [33, 35 . 37-39]. In Canada, refugee members of Sierra Leone Nationals Association were supported by the Association in preparation of their integration into the main society. The Association provided counseling assistance in "resume writing, job searching, conflict resolution, and educational workshops" [35]. All Liberian Association of Manitoba aimed to bring all Liberians and Liberian organizations together; Congolese organizations provided their members with help in their spiritual, cultural, and socio-professional integration in Canada as well as networking information [35]. In Ghana, Liberian women received social support from Liberian Refugee Women's Association and Women of Liberia Progressive Network [37]. In New Zealand, Auckland Somali Community Association, mosques, and other community organizations demonstrated the importance of their role in cultural maintenance and identity preservation [38]. (4) Ethnic Group In addition to ethnic organizations, ethnic refugee groups were also active in refugee communities in their resettlement countries/regions [37, 40-42]. During the initial settlement, Somali Clan divisions were significant in different suburbs or parts of cities [40]. Peer groups organized for cooking, sewing and bible reading among different refugee populations in Canada. Other community groups for such as women, seniors, disabled, and teenage mothers, were also favored by refugees in Canada and Ghana $[37,41]$. In a Bhutanese community in the U.S., peer-led community health workshops provided a platform for refugees to socialize, learn health-related knowledge and skills, educate each other, share information, and develop leadership and "a sense of connectedness and belonging" [42]. [5] Recreational Event Community social events often time brought people at all ages altogether [38, 40, 43]. In particular, Somalis in Australia described that sports like soccer games had no clan borders, brought Somalis together, gave them a moment of peace, and helped them meet with friends with similar ethno-cultural backgrounds, and created a sense of respect $[40,43]$. [6] Technology largely widened the connections not only locally and nationally but also internationally among refugees [23, 44, 45]. Refugees were well connected with their local, national, and international families and friends through phones, emails, and social media (e.g., Facebook) [44]. Programs like Information and Communication Technology significantly enhanced refugee communities' intra-community connectivity [45]. [7] School Ethnic schools gave the extra boost of cohesion and networking to the refugee communities [23]. Every formal schools in the Karen 
refugee camps in the Thailand-Burma borderland followed a standard curriculum developed by the Karen Education Department and adopted a centralized education system which played an important role in inter-camps' communication [23].

\subsection{Bridging Social Capital}

The following ways were clearly identified by the current literature, which were frequently adopted by refugees in their resettlement countries to reach out and network with people from a different ethnic background [22-24, 29, 30, 32, 35, 36, 38, 39, 42, 43, 45, 46-54]. (1) Work/School Refugees were well connected with people outside their group through work and/or school activities in order to receive information, build new relationships, and develop trust and mutual understanding [32, 36, 38, $39,46-51]$. For refugee students, in a study conducted in Canada, school activities, including homework assignments and after-school tutoring, provided the refugee students with opportunities to interact with other students, learn new cultures, norms, and values, and establish new friendships in their host country [47]. Schools also created student committees and voluntary extracurricular activities such as music events and sports as social bridges. These committees and activities developed mutual trust and solidarity among all students [48]. In addition, English for Speakers of Other Language classes also facilitated the interactions among multiethnic groups and enhanced the refugees' bridging social capital [39, 51]. (2) Religious Practice Religion played an important role in bridging the distance between refugees and other ethnicities [22, 23, 32, 36, 39, 46, 52]. In Tanzania, Congolese, Burundians, Rwandans and other ethnicities were connected through a religious congregation [46]. In Thailand-Burma borderland, bible schools connected Karens in the refugee camps with Thai locals, and Burmese [23]. In the U.S., refugees participated in multi-ethnic congregations and masses, and churches facilitated multi-ethnic practices [36, 52]. (3) Neighbor, Friend, and Service Provider Refugees often extended their social network through their neighbors, friends, and service providers from other ethnicities [24, 29, 36, 38, 46, 49, 50, 53]. Congolese, Burundian, and Rwandan refugees reported that they were connected with Tanzania locals or each other through a mutual friend, a relative, or an in-law [46]. Yugoslavs refugees reported themselves being connected with their Australian neighbors [49]. Somalis in New Zealand indicated that how important it was to have friendly neighborhood encounters in building bridging capital [38]. Refugees were also making connections at their workplaces, churches, human resource centers, schools, or facilities for professional services [24, 29, 50]. (4) Recreational Event "Participation in sports was significant for the development of social capital" [32]. Sports clubs included multi-ethnic players and spectators on the Somali soccer team, and Somali players also joined other ethnic teams [43]. "Sports clubs recognized differences and managed inclusively," which cultivated a multicultural network and promoted multicultural awareness among different ethnic groups [46]. In addition to sports, local social events also united people together. For instance, Liberians in Ghana were related to local Ghanaians in the petty trading [30]. (5) Ethnic Organization/Group Peer-led Bhutanese community health workshops in the U.S. discussed how to make connections and gain more information and resources outside of their community and how to make a plan to explore other neighborhoods in order to build the social capital [42]. Congolese organizations in Canada facilitated the integration of Congolese professionals at their workplaces to help with their bridging capital [35]. (6) Organization Organizations in refugee resettlement countries developed programs to help refugees reach out. A local library in Norway offered an introductory program to refugee students from Iraq, Afghanistan, Palestine, Morocco, Ethiopia, Eritrea, and Sri Lanka to communicate with Norwegian students and promote trust and safety among them [54]. [7] Technology in Australia, The Information and Communication Technology program strengthened the inter-community connectivity among refugees from Afghanistan, Bangladesh, Congo, Ghana, Liberia, Pakistan, Rwanda, Sri Lanka, and Sudan [45].

\subsection{Linking Social Capital}

Linking social capital was defined as people/groups are brought together from "different social strata in a hierarchy where power, social status, and wealth are accessed by different groups" [3]. Seven ways that refugees adopted to build their linking capital were discussed by the existing literature $[22-24,27,30-32$, 34-36, 38-40, 43, 44, 46 48, 51, 52, 55-58]. (1) Government/Non-Government Organization Government and non-government organizations were heavily involved in the refugees' resettlement [22-24, 30, 31, 38, 55-57]. In Australia, the government developed Job Network and Centrelink to help refugees from countries, including Yugoslavia, Africa, Middle East, and Somali, expand their social network and seek more job opportunities [55]. The Australia government also supported the humanitarian resettlement process and facilitated the process of opening a bank account, registering with healthcare services, securing employment benefits, enrolling in English language classes, looking for long-term housing, and receiving social security, clothing, and information [49, 56]. United Nations, United Nations High Commissioner for Refugees, Government of Ghana, World Vision International, Christian Council of Ghana, and National Catholic Secretariat assisted Liberians in the refugee camp and linked them to external resources [30]. Mae La Camp and Mae Sot in Thailand-Burma borderland connected 
Karen refugee with United Nations High Commissioner for Refugees, Ministry of the Interior of the Thai government, and non-government organizations [23]. Somali refugees in Canada participated in volunteer organizations that offered employment or mainstream agencies to learn about Canadian system, as well as joined professional organizations [24]. Cambodian refugees were well connected with multinational government and non-government organizations [22]. (2) Ethnic Organization Ethnic organizations continued to play an important role in refugees' social capital building $[23,27$, 35]. For example, in Canada, All Liberian Association of Manitoba linked refugees with a local resettlement agency and Welcome Place to assist them in being integrated into the main society of Canada and sponsoring their family members to Canada [35] Congolese organizations in Canada represented their Congolese community when dealing with political institutions [35]. (3) School/College Refugees sometimes relied on school/college to access people from different social strata $[48,51]$ Colleges in U.K. who offered English for Speakers of Other Languages classes had institutional networks with information exchange and access to resources, which refugees could be linked to [51]. School teachers helped their students be linked to financial services, such as opening a bank account [48]. (4) Media/Technology Social media and technologies increased both intra- and inter-community connectivity [23, 44, 45]. Refugees also linked themselves to a much broader world through newspaper and internet for information, employment, education, and other services, which greatly promoted social inclusion [45, 55]. (5) Recreational Event Sports did not have to have boundaries $[40,58]$. Sports not only united refugees within their own ethnic community altogether and broke the ethnic boundaries between communities [40, 43], but also linked refugees to people nationally and internationally [40]. Somali football team in Australia travelled to Swede and Canada to compete in international football events [40]. Well-trained refugee individuals served as linkage between refugee communities and government and non-government organizations through sports [43]. (6) Transnational Network Through transnational networks, refugees were actively involved in professional advocacy, interest groups, religious organizations, and political mobilization in their countries of origin and globally; websites were constructed, and networks were posted; annual meetings were organized in Australia, France, the U.S., Cambodia, and Vietnam through the United Association of Kampuchea Krom Buddhist Monks in Canada [22]. (7) Religious Practice Religious practice was crucial in all three types of social capital building [22, 23, 30, 32, 34-36, $39,46,52,58]$. In building linking capital, for example, as part of larger community outreach, local congregations provided refugees with a variety of referrals, housing, job training, education, legal assistance, and transportation, translation, healthcare and cash assistance [58].

\section{Discussion}

Findings suggested that refugees had commonly been building their bonding, bridging, and/or linking social capital through a variety of sources, including family, friends, community members, religious practice, ethnic groups and organizations, sports and other social events, workplaces, schools, and technologies in their resettlement countries [22-58]. Using these resources, they increased their community engagement and sense of belonging, strengthened their community cohesion, enhanced their social integration, and built long-term and trustworthy partnerships [22-58].

However, literature also pinpointed various obstacles that refugees encountered during the process of social capital and social network building [24, 31, 33, 38, 43, 49, 51, 59-65]. For instance, refugees were concerned about their foreign language skills the most in their host countries $[24,49,51,59,60]$. English proficiency is crucial to "obtaining work, education, friends, and getting by daily tasks" [49]. Without a job, making friends with other ethnicities was even more difficult [38]. Language barriers prevented refugees from integrating themselves into local churches. One study mentioned that all study participants spoke French fluently, which became a major barrier for them to be integrated into English-speaking South African churches [59]. At school, refugee students could not understand and express themselves properly, and hesitated to interact with other students due to a lack of confidence in English. They did not have enough opportunities to practice English outside their classroom and did not have enough vocabulary to begin with $[51,60]$. A lack of language skills also led to miscommunication and distrust [43]. Moreover, the unfamiliarity of the new culture, value, custom, norms, law, and system of their host countries became a significant barrier to refugees' network development [33, 49, 59-61]. In Australia, Australians seemed to prefer to spend more time at home where they met with their friends while refugees preferred to spend more time socializing with their friends on the streets and in cafes [49]. "The lack of familiarity with the way of life in Australia and a lack of acceptance from the Australia community" led to the isolation and loneliness in refugee communities, and led to their reliance on their own communities [61]. A study with refugees children indicated that "refugee children felt alienated in this new environment where family and lifestyles were different" [60]. Furthermore, refugees felt pressured by being judged by their physical appearance, dressing, race, education, experiences, language skills, and customs, and being verbally abused or even physical assaulted $[24,31,38,43$, 59, 61-64]. Previous data showed that refugees' experiences with discrimination were widely spread, 
which significantly lowered their confidence in interacting with other ethnic groups. It happened on the streets, in stores, restaurants, service facilities, and neighborhoods, at work and school, and from the police. The longer they lived in the place, the more incidents they reported [31, 63]. Refugees particularly feared to interact with government authorities [61,63]. "Fear of police and other authorities is a major barrier" to developing social links with government, because of their previous persecution and torture experiences [61].Other barriers that hindered refugees from widening their social capital and networks also include gender inequities led to the differences in the content and structure of social network between male and female refugees [43]; inadequate information and access to services limited the opportunities for refugees to reach out and be connected [61, 63, 65]; family conflicts resulted from refugees experiencing all the pre-migration, migration, and post-migration stress and traumas, led to the fragile kinships $[56,66]$; low self-esteem led to the hesitation to communicate [60]; Shame of asking for help led to the isolation and loneliness [36].

Throughout the years, both researchers and practitioners have been proposing different solutions including conducting support interventions, to enhance refugees' social integration in their host countries [24, 33, 60, 64, 67, 68]. Recommendations were made, including (1) provide refugees with more training programs for them to learn their host country's languages, cultures and customs, professional skills, and legal and healthcare systems[24, 33, 68]; (2) provide more programs to facilitate mutual understanding and respect and reduce racial and cultural tensions between refugee communities and host communities [64]; (3) provide refugees with more accessible access to updated and reliable information, and social and healthcare services [24, 33, 64, 68]; (4) facilitate speedy and easier family unification for refugees who have family members outside their host countries [24, 33]; [5] recognize refugees' skills and abilities they bring to their host countries and promote their self-efficacy and independency [24, 68]; [6] improve the awareness of refugees' culture among the general public in host countries prior to refugees' arrivals [24]; [6] facilitate the partnership building between refugees and government and non-government organizations in host countries; [7] provide refugee service providers with more cultural-competency trainings [24]. A support intervention was done with 58 Somali and Sudanese refugees in the U.S. the participants were given culturally relevant information and emotional support, and easy access to services, such as childcare and transportation. Trained peer and professional facilitators worked closely with the participants. They monitored participants' interactions and minimized negative social comparisons, addressed the participants' challenges of social integration, and fostered trusting relationships among them. The intervention demonstrated the effectiveness. It reconnected the participants with their ethnic community, increased their social integration, and decreased their feeling of loneliness [67].

\section{Conclusions}

Findings suggested that in resettlement countries, refugees were tied with and engaged in their own ethnic communities through their immediate family members and relatives, ethnic churches and Buddhist temples, community interest groups, a variety of refugee organizations, community social and/or sports events, as well as Facebook [22-45]. They reached out to the mainstream of the society and built trustworthy relationships through meeting with multiethnic neighbors, exploring other neighborhoods, attending local churches, making new friends at school/work, learning new cultures, norms, and customs through educational programs, and being on a multiethnic sports team $[22-24,29,30,32,35$, $36,38,39,42,43,45,46-54]$. Government and non-government organizations, including refugees' own ethnic organizations, linked refugees with different resources that can be accessed at different levels. Refugees were also actively involved in sports, professional advocacy, religious organizations, and interest groups nationally and internationally [22-24, 27, $30-32,34-36,38-40,43,44,46$ 48, 51, 52, 55-58]. Although there have been tremendous successes in refugees' social capital building, refugees also encountered significant barriers that prevent them from networking in a new country, such as inadequate language skills, discrimination, lack of information and access to resources, low self-esteem, fear of government authorities, and fragile kinships [24, 31, 33, 38, 43, 49, 51, 59-65]. Support interventions to systematically help refugees be integrated into their host countries are rare. More future endeavor is needed for a policy change and research in identifying more effective and innovative strategies of helping refugees in social integration, especially research to evaluate the effectiveness of support interventions among different refugee populations and their impact on refugees' health.

\section{REFERENCES}

[1] World Health Organization, Is social capital good for health? A European perspective, Online Available http://www.euro.who.int/_data/assets/pdf_file/0005/1700 78/Is-Social-Capital-good-for-your-health.p df

[2] K. McPherson, S. Kerr, E. McGee. The role and impact of social capital on the health and wellbeing of children and adolescents: A systematic review, Glasgow: Glasgow Centre for Population Health. Glasgow Caledonian University. Online Available http://www.gcph.co.uk/assets 
/0000/3647/Social_capital_final_2013.pdf

[3] R. R. Cottrell, J. T. Girvan, D. M. Seabert, C. Spear, \& J. F. McKenzie, J.F. Principles and foundations of health promotion and education (7th ed), Pearson Education, U.S., 2018. https://www.pearson.com/us/higher-education/progr am/Cottrell-Principles-and-Foundations-of-Health-Promoti on-and-Education-7th-Edition/PGM334975.html

[4] Centers for Disease Control and Prevention, Social Capital, Online Available https://www.cdc.gov/healthyplaces/health topics/social.htm

[5] B. d'Hombres, L. Rocco, M. Suhrcke, M. McKee. Does social capital determine health? Evidence from eight transition countries, Health Economics, Vol.19, No. 1, 56-74.

[6] D. Hurtado, I. Kawachi, J. Sudarsky. Social capital and self-rated health in Colombia: The good, the bad and the ugly, Social Science \& Medicine, Vol. 72, No. 4, 584-590.

[7] W. Poortinga. Community resilience and health: The role of bonding, bridging, and linking aspects of social capital, Health \& Place, Vol. 18, No. 2, 286-295.

[8] S. M. Mohnen, P. P. Groenewegen, B. G. M. Völker, H. D. Flap. Neighborhood social capital and individual health, Social Science \& Medicine, Vol. 72, No. 5, 660-667.

[9] J. Mithen, Z. Aitken, A. Ziersch, A. M. Kavanagh. Inequalities in social capital and health between people with and without disabilities, Social Science \& Medicine Vol. $126,26-35$.

[10] J. A. Norstrand, Q. Xu. Social capital and health outcomes among older adults in China: The urban-rural dimension. The Gerontologist, Vol. 52, No. 3, 325-334.

[11] H. Murayama, Y. Fujiwara, I. Kawachi. Social capital and health: a review of prospective multilevel studies, Journal of Epidemiology, Vol. 22, No. 3, 179-187.

[12] E. Bassett, S. Moore. Social capital and depressive symptoms: The association of psychosocial and network dimensions of social capital with depressive symptoms in Montreal, Canada, Social Science \& Medicine, Vol. 86, 96-102.

[13] F. Verduin, G. E. Smid, T. R. Wind, W. F. Scholte. In search of links between social capital, mental health and sociotherapy: A longitudinal study in Rwanda, Social Science \& Medicine, Vol. 121, 1-9.

[14] E. Landstedt, Y. B. Almquist, M. Eriksson, A. Hammarström. Disentangling the directions of associations between structural social capital and mental health: Longitudinal analyses of gender, civic engagement and depressive symptoms, Social Science \& Medicine, Vol.163, 135-143.

[15] C. Rothon, L. Goodwin, S. Stansfeld. Family social support, community "social capital" and adolescents' mental health and educational outcomes: A longitudinal study in England, Social Psychiatry and Psychiatric Epidemiology, Vol. 47, No. 5, 697-709.

[16] J. Lofors, Jonas, K. Sundquist. Low-linking social capital as a predictor of mental disorders: a cohort study of 4.5 million Swedes, Social Science \& Medicine, Vol. 64, No. 1, 21-34.
[17] M. Lee, Neighborhood residential segregation and mental health: A multilevel analysis on Hispanic Americans in Chicago, Social Science \& Medicine, Vol. 68, No. 11, 1975-1984.

[18] A. M. Almedom. Social capital and mental health: An interdisciplinary review of primary evidence, Social Science \& Medicine, Vol. 61, No. 5, 943-964.

[19] I. Kawachi, S. V. Subramanian, D. Kim. Social Capital and Health, Springer, U.S., 2008.

[20] C. J. Riumallo-Herl, I. Kawachi, M. Avendano. Social capital, mental health and biomarkers in Chile: assessing the effects of social capital in a middle-income country, Social Science \& Medicine, Vol. 105, 47-58.

[21] T. R. Wind, I. H. Komproe. The mechanisms that associate community social capital with post-disaster mental health: A multilevel model, Social Science \& Medicine, Vol. 75, No. 9, 1715-1720.

[22] J. McLellan. Cambodian Refugees in Ontario: Religious identities, social cohesion and transnational linkages, Canadian Ethnic Studies, Vol. 36, No. 2, 101-118.

[23] S. K. Lee. Scattered but connected: Karen refugees' networking in and beyond the Thailand-Burma borderland, Asian and Pacific Migration Journal, Vol. 21, No. 2, 263-285.

[24] M. Stewart, J. Anderson, M. Beiser, E. Mwakarimba, A Neufeld, L. Simich, D. Spitzer. Multicultural meanings of social support among immigrants and refugees, International Migration, Vol. 46, No. 3, 123-159.

[25] L. Simich, M. Beiser, F. N. Mawani. Social support and the significance of shared experience in refugee migration and resettlement, Western Journal of Nursing Research, Vol. 25, No. 7, 872-891.

[26] N. G. Khawaja, K. M. White, R. Schweitzer, J. Greenslade. Difficulties and coping strategies of Sudanese refugees: A qualitative approach, Transcultural Psychiatry, Vol. 45, No. 3, 489-512.

[27] P. J. Pecora, M. W. Fraser. The social support networks of Indochinese refugees, Journal of Sociology and Social Welfare, Vol. 12, 817-849.

[28] AM. M. Wallin, G. L. Ahlström. Unaccompanied young adult refugees in Sweden, experiences of their life situation and well-being: A qualitative follow-up study, Ethnicity \& Health, Vol. 10, No. 2, 129-144.

[29] N. K. Lamba. The employment experiences of Canadian refugees: Measuring the impact of human and social capital on quality of employment, Canadian Review of Sociology/Revue canadienne de sociologie, Vol. 40, No. 1, 45-64.

[30] A. Boateng. Survival voices: Social capital and the well-being of Liberian refugee women in Ghana, Journal of Immigrant \& Refugee Studies, Vol. 8, No. 4, 386-408.

[31] D. M. Barnes, R. Aguilar. Community social support for Cuban refugees in Texas, Qualitative Health Research, Vol. 17, No. 2, 225-237.

[32] J. Major, J. Wilkinson, K. Langat, N. Santoro. Sudanese young people of refugee background in rural and regional 
Australia: Social capital and education success, Australian and International Journal of Rural Education, Vol. 23, No. 3, 95-105.

[33] E. E. Pittaway, L. Bartolomei, G. Doney. The glue that binds: An exploration of the way resettled refugee communities define and experience social capital, Community Development Journal, Vol. 51, No. 3, 401-418.

[34] E. R. Canda, T. Phaobtong. Buddhism as a support system for Southeast Asian refugees, Social Work, Vol. 37, No. 1, 61-67.

[35] M. Lacroix, M. Baffoe, M. Liguori. Refugee community organizations in Canada: From the margins to the mainstream? A challenge and opportunity for social workers, International Journal of Social Welfare, Vol. 24, No. 1, 62-72.

[36] R. P. Allen. Sometimes it's hard here to call someone to ask for help: Social capital in a refugee community in Portland, Maine, Massachusetts Institute of Technology, 2007.

[37] A. Boateng. A mixed methods analysis of social capital of Liberian refugee women in Ghana, Journal of Sociology and Social Welfare, Vol. 36, No. 3, 59-81.

[38] S. Elliott, I. Yusuf. "Yes, we can; but together": Social capital and refugee resettlement, Kotuitui: New Zealand Journal of Social Sciences Online, Vol. 9, No. 2, 101-110.

[39] L. J. Goodson, J. Phillimore. Social Capital and Integration: The Importance of Social Relationships and Social Space to Refugee Women, International Journal of Diversity in Organisations, Communities \& Nations, Vol. 7, No. 6, 181-193.

[40] R. Spaaij. Refugee youth, belonging and community sport. Leisure Studies, Vol. 34, No. 3, 303-318.

[41] B. Behnia. Refugees' convoy of social support: Community peer groups and mental health services, International Journal of Mental Health, Vol. 32, No. 4, 6-19.

[42] H. Im, R. Rosenberg. Building social capital through a peer-led community health workshop: A pilot with the Bhutanese refugee community, Journal of Community Health, Vol. 41, No. 3, 509-517.

[43] R. Spaaij. Beyond the playing field: Experiences of sport, social capital, and integration among Somalis in Australia, Ethnic and Racial Studies, Vol. 35, No. 9, 1519-1538.

[44] L. Williams. Social networks of refugees in the United Kingdom: Tradition, tactics and new community spaces, Journal of ethnic and migration studies, Vol 32, No. 5, 865-879.

[45] K. Alam, S. Imran. The digital divide and social inclusion among refugee migrants: A case in regional Australia, Information Technology \& People, Vol. 28, No. 2, 344-365.

[46] R. Willems. Coping with displacement: Social networking among urban refugees in an east African context, Trans Pacific Press, Australia, 2005, 53-77.

[47] L. Naidoo. Developing social inclusion through after-school homework tutoring: A study of African refugee students in Greater Western Sydney, British Journal of Sociology of Education, Vol. 30, No. 3, 261-273.
[48] G. Smyth, G. MacBride, G. Paton, N. Sheridan. Social capital and refugee children: Does it help their integration and education in Scottish schools? Diskurs Kindheits-und Jugendforschung, Vol. 5, No. 2, 145-157.

[49] M. R. Keel, N. M. Drew. The settlement experiences of refugees from the former Yugoslavia: Acculturation, ethnic identity, ethnicity, community and social network development. Community, Work \& Family, Vol. 7, No. 1, 95-115.

[50] N. K. Lamba, H. Krahn. Social capital and refugee resettlement: The social networks of refugees in Canada, Journal of International Migration and Integration/Revue de l'integration et de la migration international, Vol. 4, No. 3, 335-360.

[51] A. Dimitriadou. The Formation of social capital for refugee students: An Exploration of ESOL settings in two further education colleges, Educate, Vol. 4, No. 1, 31-45.

[52] R. Allen. The bonding and bridging roles of religious institutions for refugees in a non-gateway context, Ethnic and Racial Studies, Vol. 33, No. 6, 1049-1068.

[53] M. Jerusalem, A. Hahn, R. Schwarzer. Social bonding and loneliness after network disruption: A longitudinal study of East German refugees, Social Indicators Research, Vol. 38, No. 3, 229-243.

[54] A. Vårheim. Trust and the role of the public library in the integration of refugees: The case of a Northern Norwegian city, Journal of Librarianship and Information Science, Vol. 46, No. 1, 62-69.

[55] S. Torezani, V. Colic-Peisker, F. Fozdar. Looking for a "Missing Link": Formal employment services and social networks in refugees' job search, Journal of Intercultural Studies, Vol. 29, No. 2, 135-152.

[56] C. McMichael, L. Manderson. Somali women and well-being: Social networks and social capital among immigrant women in Australia, Human Organization, Vol. 63, No. 1, 88-99.

[57] H. Beirens, N. Hughes, R. Hek, N. Spicer. Preventing social exclusion of refugee and asylum seeking children: Building new networks, Social Policy and Society, Vol. 6, No. 2, 219-229.

[58] N. Ives, J. W. Sinha, R. Cnaan. Who is welcoming the stranger? Exploring faith-based service provision to refugees in Philadelphia, Journal of Religion \& Spirituality in Social Work: Social Thought, Vol. 29, No. 1, 71-89.

[59] V. Nzayabino. The role of refugee-established churches in integrating forced migrants: A case study of Word of Life Assembly in Yeoville, Johannesburg. HTS Theological Studies, Vol. 66, No. 1, 1-9.

[60] D. B. Seker, I. Sirkeci. Challenges for refugee children at school in Eastern Turkey, Economics \& Sociology, Vol. 8, No. 4, 122-133.

[61] E. Pittaway, C. Muli, S. Shteir. "I have a voice-hear me!" Findings of an Australian study examining the resettlement and integration experience of refugees and migrants from the Horn of Africa in Australia. Refuge: Canada's Journal on Refugees, Vol. 26, No. 2, 133-146.

[62] R. Deuchar. "People look at us, the way we dress, and they 
think we're gangsters": Bonds, bridges, gangs and refugees: a qualitative study of inter-cultural social capital in Glasgow, Journal of Refugee Studies, Vol. 24, No. 4 , 672-689.

[63] I. Correa-Velez, R. Spaaij, S. Upham. "We are not here to claim better services than any other': Social exclusion among men from refugee backgrounds in urban and regional Australia, Journal of Refugee Studies, Vol. 26, No. 2, 163-186.

[64] F. Fozdar, L. Hartley. Civic and ethno belonging among recent refugees to Australia. Journal of refugee studies, Vol. 27, No. 1, 26-144.

[65] N. Spicer. Places of exclusion and inclusion: Asylum-seeker and refugee experiences of neighbourhoods in the UK, Journal of ethnic and migration studies, Vol. 34,
No. 3, 491-510.

[66] C. McMichael, S. M. Gifford, I. Correa-Velez. Negotiating family, navigating resettlement: Family connectedness amongst resettled youth with refugee backgrounds living in Melbourne, Australia, Journal of Youth Studies, Vol. 14, No. 2, 179-195.

[67] M. Stewart, L. Simich, E. Shizha, K. Makumbe, E. Makwarimba. Supporting African refugees in Canada: Insights from a support intervention. Health \& Social Care in the Community, Vol. 20, No. 5, 516-527.

[68] J. R. Goodkind, J. M. Hess, B. Isakson, M. LaNoue, A. Githinji, N. Roche, K. Vadnais, D. P. Parker. Reducing refugee mental health disparities: A community-based intervention to address postmigration stressors with African adults, Psychological Services, Vol. 11, No. 3, 333-345. 